\title{
O DEVER FUNDAMENTAL DE PROTEÇÃO DO MEIO AMBIENTE MARINHO COMO CONSEQUÊNCIA DA AVARIA MARÍTIMA E PORTUARIA ${ }^{1}$
}

\author{
Daury Cesar Fabriz \\ Marcelo Fernando Quiroga Obregón ${ }^{3}$
}

\begin{abstract}
Resumo
O presente artigo pretende analisar uma das formas de destruição do meio ambiente marinho dentro dos espaços marítimos como consequência da navegação e transporte aquaviário tanto em águas nacionais como internacionais; a avaria marítima e portuária como um fator de poluição ambiental provocada por atitudes e decisões humanas. As avarias marítimas e portuárias motivo do presente trabalho devem ser analisadas a partir do artigo $225 \$ 1^{\circ}$ e $4^{\circ} \mathrm{da} \mathrm{CF} / 88$, tendo como base teórica a doutrina do direito marítimo de autores nacionais tais como Eliana Otaviano , Carla Adriana Comitre Gibertoni e Clarissa Ferreira Macedo D’lesp, assim como a respectiva legislação nacional (Código Comercial) e internacional ( Regras de York e Antuérpia 2004), insistindo, que a responsabilidade (deveres fundamentais) seja compartilhada entre o Estado, as pessoas jurídicas e as pessoas físicas que participam da atividade marítima através do transporte de mercadorias e passageiros
\end{abstract}

Palavras-chave: Avaria marítima e portuária; dever fundamental; transporte marítimo; sustentabilidade.

\section{INTRODUÇÃO}

A destruição do meio ambiente marinho é uma preocupação constante da sociedade internacional e do conjunto da sociedade civil vítima da degradação ambiental. Em anteriores trabalhos, abordamos diferentes formas de poluição ambiental marinha especialmente como consequência de derramamento de óleo e de troca de água de lastro e a necessidade de assumir deveres fundamentais a fim de evitar a continuidade deste tipo de violação.

Em se tratando dos fatos acima mencionados, houve uma preocupação para a elaboração de normas

\footnotetext{
${ }^{1}$ Artigo científico, apresentado ao curso de Doutorado em Direitos e Garantias Fundamentais da Faculdade de Direito de Vitória FDV -, desenvolvido junto ao grupo de pesquisa, Estado, Democracia Constitucional e Direitos Fundamentais, coordenado pelo professor Doutor Daury Cesar Fabriz.

${ }^{2}$ Professor Associado da Universidade Federal do Espírito Santo. Doutor em Direito pela Universidade Federal de Minas Gerais. Professor da Faculdade de Direito da Faculdade de Vitória - FDV - Coordenador do Grupo de Pesquisa: Estado, Democracia Constitucional e Direitos Fundamentais. Presidente da Academia Brasileira de Direitos Humanos - ABDH. E-mail: daury@terra.com.br

${ }^{3}$ Discente do curso de doutorado em Direitos e Garantias Fundamentais da Faculdade de Direito de Vitória - FDV - Mestre em Direito Internacional e Direito Comunitário pela PUC-MG. Coordenador Acadêmico da Especialização em Direito Marítimo e Portuário da FDV. Professor de Direito Internacional e Direito Marítimo e Portuário da FDV.E-mail: mfqobregón@yahoo.com.br
} 
internacionais e leis internas a fim de prevenir e fiscalizar estas formas de violação ambiental originarias do transporte de carga marítimo, especificamente petróleo e seus derivado, os mesmos que a partir da década dos 60 cresceram de maneira alarmante pelo volume de consumo destes recursos naturais numa sociedade preocupada com o bem-estar econômico e eminentemente consumista

Observamos que o transporte de petróleo e a troca de água de lastro não são os únicos causadores da destruição do meio ambiente marinho e do seu ecossistema, o derramamento de todo tipo e forma de lixo desde os esgotos urbanos, esgotos sanitários dos navios, lama contaminada com minerais pesados provenientes de acidentes de barragens em águas interiores (Mariana), etc.

Neste trabalho abordamos a contaminação marinha através das avarias marítimas e portuárias, duas formas de poluição que não se encontram reguladas pelas normas internacionais nem internas, mas que podem provocar a destruição do meio ambiente marinho nos diferentes espaços marítimos previstos pela legislação internacional.

Na primeira parte do trabalho faremos uma explicação do conceito doutrinário da avaria marítima ou avaria grossa e a avaria simples ou particular, diferenciando-a da varia portuária . Esta forma de incidente marítimo conhecido desde a Antiguidade encontra-se vigente na atualidade e previsto nos contratos de navegação e de transporte de mercadorias, assim como nas legislações internas e internacionais, incidentes que acarretam graves danos no meio ambiente marinho e que até hoje não existe legislação especifica para prevenir, regulamentar e fiscalizar esta forma de destruição ambiental como consequência do alto risco da aventura marítima.

Esclarecemos também, a diferença da avaria marítima com a avaria portuária, a mesma que acontece nas instalações dos terminais portuários, quando os navios se encontram atracados e realizando a operação de embarque e desembarque de mercadorias e passageiros, manipulação de cargas perigosas, contendo produtos tóxicos, afetando não somente a instalação portuária como também os espaços urbanos onde se encontra instalado o terminal, esta operação encontra-se sob responsabilidade dos operadores portuários como previsto na Nova Lei dos Portos -Lei 12.815, de05 de junho de 2013.

Posteriormente analisaremos as consequências destas avarias marítimas e portuárias na destruição do meio ambiente marinho e a necessidade de elaborar normas adequadas para poder prevenir e regular este tipo de acidentes que podem ser cometidos de maneira intencional a fim de salvar o casco do navio, a carga e à própria tripulação como é o caso da avaria grossa, ou pode acontecer por motivos de negligência ou má arrumação no caso de avaria simples ou particular e finalmente por avaria portuária.

Observamos que nenhum deste fatos da navegação esta previsto em normas encarregadas de regular violações ao meio ambiente marinho como consequência de poluição ambiental por carga alijada ao mar ou em instalações portuárias. 
Na última parte do trabalho, abordamos as formas de participação do Poder Público e da sociedade no controle, fiscalização e prevenção das diversas formas de violação ambiental e consequente destruição do ecossistema marinho, dando ênfase no dever fundamental das partes de maneira compartilhada na proteção do meio ambiente para as gerações presentes e futuras.

Finalmente, frente a dicotomia da proteção do meio ambiente e a necessidade do desenvolvimento econômico, fazemos uma analise das formas de desenvolvimento sustentável que devem ser adotadas pelo Poder Público a fim de preservar e proteger o meio ambiente.

\section{AVARIA MARÍTIMA: GROSSA E AVARIA SIMPLES OU PARTICULAR. AVARIA PORTUÁRIA}

O Código Comercial Brasileiro, no seu artigo 761 especifica que avaria marítima são "Todas as despesas extraordinárias feitas a bem do navio ou da carga, conjunta ou separadamente, e todos os danos acontecidos àquela ou a esta, desde o embarque ou a partida até a sua volta e desembarque", em relação a o tema, poderíamos afirmar que a totalidade das normas nacionais e internacionais coincidem com a definição do nosso código comercial, isto porque o direito marítimo é um direito consuetudinário, baseado nas práticas da Antigüidade e que não se modificaram com o passar dos tempos, elas se mantém vigentes, fazem parte dos ordenamentos jurídicos da maioria dos Estados-membros da sociedade internacional.

A preocupação do legislador com a integridade do navio e a segurança da tripulação, assim como a preservação da carga, estão relacionadas ao transporte marítimo, tão perigoso antigamente como nos dias atuais, mas ao mesmo tempo, a forma mais utilizada nas relações comerciais ao redor do mundo, na atualidade, $90 \%$ do transporte de mercadorias é feita através de navios com diferentes especialidades ou características de uso como navios petroleiros, porta containeres, graneleiros sólidos, graneleiros líquidos, rollom-rollof (transporte de veículos), off shore (navios de apoio a plataformas marítimas), etc.

Durante a viagem ou expedição marítima, estas embarcações podem sofrer uma serie de avarias como conseqüência das inclemências do tempo, dos desígnios da natureza, conhecidos no direito marítimo como fortuna do mar ou perigos do mar. Eliane Octaviano afirma que "No direito marítimo, a palavra avaria (average) significa despesas ou danos extraordinários concernentes ao navio e/ou carga. Assim, os danos e as despesas resultantes ou provenientes dos riscos, da fortuna do mar e dos acidentes da navegação são consignados como avarias marítimas." Existem, no direito marítimo, dois tipos ou formas de avarias, as avarias simples ou particulares e as avarias grossas, cada uma delas possuem características diferentes, embora as duas signifiquem, conforme a nossa legislação acima citada, despesas extraordinárias feitas, como resultado do transporte marítimo, isto para diferenciar das avarias portuárias que são o resultado do embarque e desembarque de mercadorias e passageiros 
nas instalações portuárias.

As avarias grossas, podem ser consideradas como um instituto do direito marítimo Cremoneze confirma que "Trata-se de uma figura tradicional do Direito Marítimo e que se confunde com a própria história da navegação, até porque de âmbito internacional”’, a principal característica da avaria grossa é que é uma consequência de um ato intencional praticada pelo comandante como uma forma de proteção do navio, da tripulação e da própria mercadoria transportada a bordo do navio, na iminência de perigo durante a viagem, sendo que as despesas emergentes deste ato, deveram ser pro rateadas proporcionalmente entre o armador, o transportador e os proprietários da mercadoria transportada.

As normas internacionais como as Regras de York e Antuérpia 2004, Regra A, 1 e 2, assim como a legislação nacional, Código Comercial, artigos 764 e 765 definem claramente quais os incidentes marítimos que caracterizam uma avaria grossa. As primeiras, foram criadas em 1864 para regular e uniformizar os incidentes marítimos considerados como avaria grossa, revisadas em junho de 2004, na cidade de Vancouver Canadá, e como afirma Otaviano, aplicadas e incorporadas nos contratos de transporte marítimo e de políticas de seguros a partir de 01/01/2005.

As Regras de York e Antuérpia 2004, estabelecem que na regulação de avaria grossa devem ser aplicadas as estabelecidas neste corpo de leis, incluindo-se qualquer lei e prática incompatíveis com elas. Na regra preponderante, afirma que em nenhum caso haverá crédito por sacrifício ou despesa, a menos que razoavelmente feito ou incorrido.

A Regra A 1 da norma internacional especifica de maneira contundente, que "Um ato caracteriza-se como de avaria grossa, e somente quando, implicar um sacrifício, ou despesa, extraordinário, intencional e razoavelmente feito para a segurança comum e no sentido de preservar do perigo os bens envolvidos na mesma expedição marítima”. No numeral 2, enfatiza que "Os sacrifícios e despesas de avaria grossa serão suportados pelos diferentes interesses contribuintes...".

O Código Comercial Brasileiro, no seu artigo 764 estabelece e dispõe o seguinte em relação às avarias grossas: "São avarias grossas tudo o que se dá ao inimigo, corsário ou pirata por composição ou a título de resgate do navio e fazendas, conjunta ou separadamente", acrescentado de mais 21 incisos que especificam claramente as características da avaria grossa, assim como as coisas alijadas para salvação comum, os cabos,mastros, velas e outros quaisquer aparelhos deliberadamente cortados ou partidos por força de vela para salvação do navio e carga; as ancoras, amarras e quaisquer outras coisas abandonadas para salvamento ou beneficio comum; os danos causados pelo alijamento às fazendas restantes a bordo; os danos feitos deliberadamente ao navio para facilitar a

\footnotetext{
${ }^{4}$ CRENONEZE, Paulo Henrique. Prática de Direito Marítimo: O contrato de transporte marítimo e a responsabilidade civil do transportador. 2a ed. Revisada, atualizada e ampliada. São Paulo: Quartier Latin, 2012, p. 295.
} 
evacuação de água e os danos acontecidos por esta ocasião à carga; os direitos de pilotagem, e outros de entrada e saída num porto de arribada forçada;os danos acontecidos ao corpo e quilha do navio, que premeditadamente se faz varar para prevenir perda total, ou presa do inimigo; o premio do seguro das despesas de avaria grossa, e as perdas sofridas na venda da parte da carga no porto de arribada forçada para fazer face às mesmas despesas; as custas judiciais para regular as avarias.

O mesmo corpo de leis conclui que avaria grossa em geral, são todos os danos causados deliberadamente em caso de perigo ou desastre imprevisto, e sofridos como conseqüência imediata destes eventos, bem como as despesas feitas em iguais circunstancias, depois de deliberações motivadas, em bem e salvamento comum do navio e mercadorias, desde a sua carga e partida até o seu retorno e descarga. Observamos que em nenhum dos incisos acima citados se faz menção à proteção do meio ambiente marinho, nem se define responsabilidades civis caso aconteça dano ambientas como conseqüência da avaria grossa.

Entre os acidentes que caracterizam a avaria grossa, é possível mencionar o alijamento, a arribada , a recalada e a varação, conforme ensina Eliane Otaviano 5 , "define-se alijamento como o ato voluntário de lançar ao mar as mercadorias ou qualquer outro bem - v.gaprestos ou acessórios - do navio.

O alijamento, não obstante configurar ato voluntario, poderá ou não ser enquadravel em avaria grossa. Com efeito, as avarias decorrentes do alijamento serão consideradas avarias grossas se atenderem aos requisitos fundamentais".

A arribada forçada é uma mudança de rota de viagem por diferentes motivos, que no caso brasileiro, encontram-se especificados no artigo 741 do Código Comercial : "Quando um navio entra por necessidade em algum porto ou lugar distinto dos determinados na viagem a que se propusera, diz-se que fez arribada forçada", seja por falta de viveres, acidente acontecido à equipagem, à carga ou ao próprio navio, epidemia ou doença grave que impossibilite este a continuar a navegar e temor fundado de inimigo ou ataque pirata, hoje em dia muito comum nas costas da Somália quando navios petroleiros são abordados em troca de altas quantias de dinheiro.

Quando um navio zarpa de um porto de maneira programada e posteriormente deve retornar ao mesmo porto de maneira forçada, esta operação é considerada como recalada.

O encalhe voluntario com o objetivo de salvar ou preservar o navio, a mercadoria transportada, a vida e segurança da tripulação em considerado co varação. Todas estas hipóteses de acidentes, são consideradas pela doutrina como sendo os elementos principais para considerar o fato com avaria grossa .

Para que o incidente marítimo seja enquadrado como avaria grossa, caracterizada por um ato humano, realizado de maneira intencional a fim de evitar uma serie de danos a bordo do navio durante a expedição marítima, a legislação exige, que se cumpram uma serie de pressupostos, tais como a extraordinariedade,

${ }_{5}^{5}$ OCTAVIANO MARTINS, Eliane Maria. Curso de direito marítimo., volume II. Barueri, SP: Manole,2008 p. 61. vol.11, no. 02, Rio de Janeiro, 2018. pp. 1897 - 1911 
intencionalidade, razoabilidade e comunidade de interesses conforme explica Otaviano ${ }^{6}$, "Preliminarmente para que sejam alocáveis como avaria grossa, é indispensável que despesa ou dano intencional se revistam de extraordinariedade, isto é,não estejam previstos na expedição marítima”.

O dano deve ser provocado intencionalmente por decisão do comandante como consequência de iminência de perigo grave, cujo resultado signifique despesas ou danos ao conjunto da expedição marítima, quer dizer, tripulação, navio e carga, afetando ao conjunto ou à comunidade de interesses.

As avarias simples ou particulares assim como as avarias grossas, são consideradas também, como despesas extraordinárias, com características diferentes. $\mathrm{O}$ ato ou o fato é unicamente realizado em beneficio de uma das partes da expedição marítima e as despesas deverão ser pagas em forma separada ou individual ou seja por aquele que ocasionou o dano, seja o armador, o afretador ou o proprietário ou proprietários da mercadoria transportada.

O Código Comercial Brasileiro no seu artigo 766 incs. 1 a 5 estabelece que, são avarias simples e particulares, o dano acontecido às fazendas por borrasca, presa, naufrágio, ou encalhe fortuito , durante a viagem, $\mathrm{e}$ as despesas feitas para salvar; a perda de cabos, amarras, âncoras, velas e mastros,causada por borrasca ou outro acidente do mar; as despesas de reclamação do navio e da carga durante o tempo de riscos devem ser feitas separadamente. Carla Adriana Gibertoni ${ }^{7}$, concordando com o Codigo Comercial, esclarece que "Avaria simples ou particular é a que a vontade humana não intervém para resguardar interesses relativos ao navio ou à carga; decorrem de casos fortuitos ou de força maior, de imprudência, imperícia ou negligência, de dolo do comandante, equipagem ou empregados do armador,ou até de terceiros. É a avaria que recai sobre o bem transportado e tem como exclusivo responsável o transportador". A mesma autora afirma que, em casos de forte tempestade ou borrasca, o armador e fretador ficam isentos de responsabilidade, onerando unicamente ao segurador. Assim como nos casos de avaria grossa, nos casos de avaria simples ou particular, não existe qualquer disposição ou previsão legal no Código Comercial que trate sobre proteção ambiental do meio ambiente marinho.

Faz-se necessário diferenciar as avarias marítimas sejam elas particulares ou grossas das avarias portuárias, as primeiras, grossa e particular, surgem a partir do momento em que a mercadoria encontra-se a bordo do navio, para serem transportadas sob a responsabilidade do comandante, e as segundas, são aquelas derivadas da movimentação de mercadorias e passageiros através da operação portuária no embarque e desembarque dentro das instalações portuárias.

A Lei 12.815 de 05 de junho de 2013 que dispõe sobre a exploração direta e indireta pela União dos portos e instalações portuárias e sobre as atividades desempenhadas pelos operadores portuários, dispõe nos seus

\footnotetext{
${ }^{6}$ OCTAVIANO MARTINS, Eliane Maria. Curso de direito marítimo., volume II. Barueri, SP: Manole,2008, p. 5-7.

${ }^{7}$ GIBERTONI, Carla Adriana Comitre. Teoria e Prática do Direito Marítimo. 3.ed., atualizada, revista e ampliada. Rio de Janeiro: Renovar, 2014, p. 291.
} 
artigos 25, 26, 27 e 28, que cabe a estes últimos a atividade de movimentação de carga, assumindo a responsabilidade, respondendo perante a Administração do Porto Organizado, pelos danos culposamente causados à infraestrutura, às instalações, e ao equipamento de que a administração do porto seja titular, que se encontre a seu serviço ou sob sua guarda; ao proprietário ou consignatário da mercadoria pelas perdas e danos que ocorrerem durante as operações que realizar ou em decorrência delas; o armador pelas avarias ocorridas na embarcação ou na mercadoria dada a transporte. Assim como a responsabilidade perante outros entes tais como o OGMO e à autoridade aduaneira.

Desta maneira, as avarias portuárias estão previstas na legislação pertinente (artigo 26, incs. I a VIII) de maneira detalhada indicando o operador portuário como responsável na movimentação de mercadorias perante a administração do porto pelos danos culposamente causados à infraestrutura, às instalações e ao equipamento de que a administração do porto seja titular, que se encontre a seu serviço ou sob sua guarda; perante o proprietário ou consignatário da mercadoria pelas perdas e danos que ocorrerem durante a operação; perante o armador pelas avarias ocorridas na embarcação ou na mercadoria dada a transporte; perante o trabalhador portuário pela remuneração dos serviços prestados e respectivos encargos; aos órgãos competentes pelo recolhimento dos tributos incidentes sobre o trabalho portuário avulso; à autoridade aduaneira pelas mercadorias sujeitas a controle aduaneiro, no período em que lhe estejam confiadas ou quando tenha controle ou uso exclusivo da área onde se encontrem depositadas ou devam transitar. Podemos observar que não existe nenhuma norma que estabeleça ou imponha obrigações ao operador portuário a fim de que também se responsabilize com a prevenção e proteção do meio ambiente durante as operações de embarque e desembarque de mercadorias dentro das instalações portuárias e que possam afetar ou contaminar o meio ambiente marinho.

A Lei 12.815 de 05 de junho de 2013, conhecida também como "Nova Lei dos Portos". Prevê no seu artigo 17 que a Administração do porto organizado e/ou instalação portuária, é exercida diretamente pela União, pela delegatária ou pela entidade concessionária do porto organizado, delegando uma serie de competências previstas no presente artigo e nos quinze incisos correspondentes, tais como a obrigatoriedade de cumprir e fazer cumprir as leis, os regulamentos e os contratos de concessão ; assegurar o gozo das vantagens decorrentes do melhoramento e aparelhamento do porto ao comercio e à navegação, pré-qualificar os operadores portuários, de acordo com as normas estabelecidas pelo poder concedente; ou executar as obras da construção, reforma, melhoramento e conservação das instalações portuárias, assim como fiscalizar a operação portuária, zelando pela realização das atividades com regularidade, eficiência, segurança e respeito ao MEIO AMBIENTE.

Então podemos afirmar que, na avaria portuária realizada através da operação portuária existe previsão legal de proteção do meio ambiente do conjunto da instalação portuária através da autoridade do porto constituída pela Administração, a mesma que ao pré-qualificar ao operador portuário deverá exigir o 
cumprimento da preservação do meio ambiente, esta mesma previsão se encontra ausente na avaria marítima tanto grossa quanto particular.

Francisco de Morais ${ }^{8}$ afirma que: "Como toda responsabilidade civil direcionada pela norma, cabe à instalação portuária zelar pela segurança e incolumidade da carga que recebe para armazenagem, seja no embarque, seja no desembarque marítimo, e isto desde seu recebimento até a efetiva entrega ao seu destinatário navio ou consignatário da carga".

Por tanto, as avarias marítimas estão vinculadas ao transporte de mercadorias sob a responsabilidade do transportador e as avarias portuárias estão relacionadas com a movimentação e armazenamento das mesmas nas instalações portuárias sob a responsabilidade do operador portuário e da administração do porto quando a mesma se encontra nos armazéns.

\section{AS CONSEQÜÊNCIAS DA AVARIA MARÍTIMA E PORTUÁRIA NA DESTRUIÇÃO DO MEIO AMBIENTE MARINHO. ANÁLISE DA LEGISLAÇÃO NACIONAL E INTERNACIONAL}

O derramamento de óleo e a troca de água de lastro durante o transporte marítimo, não são os únicos acidentes marítimos que destroem o meio ambiente marinho, embora exista uma vontade internacional de prevenir este tipo de desastre através da elaboração de normas nacionais e convenções internacionais que criam regras vinculantes para a preservação do meio ambiente marinho, os resultados são pouco ou nada eficazes, isto, como conseqüência dos interesses econômicos envolvidos no transporte do petróleo e a falta de investimento em tecnologia ou mecanismos para evitar, prevenir ou reparar os danos causados ao meio ambiente marinho.

Nas águas interiores tais como, instalações portuárias, e no mar territorial, área marítima com extensão de 12 milhas marítimas a partir da linha de base ou de preamar (delimitação conforme a norma internacional), os danos ambientais também são frequentes nas operações de embarque e desembarque de mercadorias ou na troca de água de lastro, conhecida como bioinvasão, Isto é, reprodução de espécies exóticas alheias ao ecossistema local , acarretando inúmeros danos à sociedade.

Ao analisarmos a legislação internacional em relação à proteção ambiental marinha, podemos observar que no artigo 204 inc. $2^{\circ}$ da Convenção das Nações Unidas sobre Direito do Mar, conhecida como Convenção de Montego-Bayse reafirma que os Estados devem manter, sob vigilância, os efeitos de quaisquer atividades por eles autorizadas ou a que se dediquem, a fim de determinarem se as referidas atividades são suscetíveis de poluir o meio marinho. O artigo 194 estabelece ainda, que os Estados devem tomar todas as medidas necessárias para prevenir, reduzir e controlar a poluição do ambiente marinho, o artigo 235 da mesma Convenção, prevê que os 
Estados cooperem na elaboração de regras pertinentes sobre direito internacional, com o objetivo de assegurar uma pronta e adequada indenização com respeito a qualquer dano causado pela poluição do ambiente marinho.

A Convenção Internacional para a Prevenção da Poluição por Navios (MARPOL 73/78), regula em forma especifica o controle, prevenção e proteção do meio marinho contra a poluição causada por navios, especialmente navios petroleiros, também define as características técnicas, capacidade de carga, vistorias periódicas, a intervalos determinados, mas não excedendo os 5 anos, que permitam assegurar que a estrutura, equipamento, sistemas,instalações, disposições e materiais cumpram integralmente os requisitos do texto da Convenção e qualquer outra forma que altere o navio, de maneira que satisfaça os requisitos exigidos pela Convenção, isto, como medida preventiva a fim de evitar vazamento de óleo por causa da má conservação.

A MARPOL 73/78, no seu Anexo II. Regra 3, classifica em 4 categorias e lista das substancias liquidas nocivas, as que representam: (1) um risco grave,(2) um risco, (3) fraco risco e (4) reconhecido risco para os recursos marinhos ou para a saúde humana ou prejudicam gravemente os locais de recreio ou outras utilizações legitimas do mar e justificam, portanto, a aplicação de medidas rigorosas contra a poluição.

O Anexo IV se refere às Regras para a prevenção da poluição por esgotos sanitários dos navios , conforme a Regra I, “Esgotos sanitários” significa:

a) Águas de drenagem e outros resíduos provenientes de qualquer tipo de casas de banho, urinóis e embornais de retrete;

b) Águas de drenagem provenientes de instalações médicas (dispensários, enfermarias, etc.) através de lavatórios, banheiras e embornais localizados nessas instalações;

c) Águas de drenagem provenientes de compartimentos contendo animais vivos, ou

d) Outras águas residuais, quando misturadas com águas de drenagem acima referidas". Esta regra será aplicada também a navios de turismo ou cruzeiros marítimos, com capacidade para milhares de passageiros, através de vistorias, verificando que o navio esteja equipado com instalações de tratamento de esgotos ou sistemas de desintegração e desinfecção de esgotos sanitários aprovados pela administração da Convenção.

A Convenção Internacional Sobre Responsabilidade Civil Por Dano Causado Por Poluição Por Óleo do

Próprio Navio, 2001, estabelece no seu artigo 1 inciso 9 que, "Dano por poluição” significa:

perda ou dano causado exteriormente ao navio por contaminação resultante de vazamento ou derramamento de óleo do próprio navio, onde quer que tal vazamento ou derramamento ocorra, desde que a indenização pelo prejuízo ao meio ambiente, seja limitada aos custos de medidas razoáveis de restauração efetivamente tomadas, ou a serem tomadas;...", o Acordo Internacional dispõe que a mesma deve aplicar-se exclusivamente a dano causado por poluição, estabelecendo responsabilidades para o armador.

Podemos observar que, a MARPOL 73/78, é um acordo internacional especifico sobre responsabilidade civil por dano causado por poluição por derramamento de óleo do próprio navio, mas pode ser utilizada como um instrumento jurisprudencial para prevenir qualquer forma de poluição, posto que define "Dano por poluição" de uma maneira geral, especificando as responsabilidades para este tipo de prática.

\footnotetext{
${ }^{8}$ SILVA, Francisco Carlos Morais. Manual de Direito Portuário. Vila Velha: Above publicações, 2013, p. 212.
} 
A preocupação com o meio ambiente marinho assim como as recomendações da Convenção das Nações Unidas sobre o Direito do Mar no parágrafo $1^{\circ}$ do seu artigo 196, impulsionou à sociedade internacional a concluir uma outra Convenção relacionada com a troca de água de lastro, resultando na Convenção Internacional para Controle e Gerenciamento de água de Lastro e Sedimentos de Navios, o texto da Convenção foi aprovado pelo Brasil através do Decreto Legislativo 148/10 de 15 de março de 2010. A IMO (Organização Marítima Internacional), agência da ONU responsável pela segurança da navegação e prevenção da poluição ambiental, adotou a Convenção em 13 de fevereiro de 2004.

A Convenção reconhece que a descarga descontrolada de água de Lastro e dos Sedimentos nela contidos, descarregados por navios, levou a transferência de Organismos Aquáticos Nocivos e Agentes Patogênicos, causando perdas e danos ao meio ambiente, à saúde pública e às propriedades recursos dos centros urbanos. Define no seu Anexo II Regra I o que é um navio tanque para transporte de produtos químicos; Lastro limpo; Lastro segregado e substancias liquidas nocivas, fornecendo dados e tabelas técnicas para o seu controle e verificação permanente.

A Regra 3 , classifica as substâncias liquidas nocivas em quatro categorias, sendo que a Categoria A, representa substancias liquidas que representam um risco grave; a Categoria B, representa substâncias liquidas que representam um risco; a Categoria $C$, representa substâncias liquidas que representam fraco risco e a Categoria $\mathrm{D}$, representa substâncias liquidas que representam um reconhecido risco.

Pela analise feita dos diferentes acordos internacionais realizados pela sociedade internacional, observamos que não existe nenhum instrumento legal que previna, minimize ou elimine os riscos de poluição ambiental através de avarias marítimas ou portuárias, assim como não existe norma interna que observe e regulamente poluição por avaria marítima ou portuária.

Ao analisarmos o instituto da avaria marítima e portuária, podemos observar que através dos mesmos ou como consequência das avarias, existe uma grande probabilidade de poluir o meio ambiente marinho e portuário; as consequências de uma avaria marítima seja grossa ou simples podem ter um impacto muito grande na contaminação do meio ambiente marinho, posto que a carga a ser alijada pode conter elementos altamente perigosos para a contaminação ambiental, lembrando que os navios transportam todo tipo de carga desde alimentos até produtos com conteúdo tóxico.

Nos casos de avaria portuária, a mesma que acontece no momento da carga e descarga da mercadoria, assim como nos casos de troca de água de lastro dentro das instalações portuárias, a poluição e o dano ambiental afetam não somente o ambiente marinho da área portuária, como também as áreas urbanas onde se encontra a instalação portuárias. Embora exista a previsão legal de proteção ambiental na Nova Lei dos Portos, consideramos que não é suficiente nem eficaz, devendo elaborar normas especificas e adequadas para as diferentes instalações 
portuárias conforme a sua função específica ou especialidade (petroleiros, granel liquido, granel solido, produtos químicos, off shore, químicos etc.)

Marcos Maia e Sergio Grein afirmam que o ambiente portuário é muito complexo e que deveria haver uma ordenação especifica para poder regular e prevenir qualquer dano ambiental, os mesmos afirmam que : “...devendo terminar com a implementação de um Sistema de Gestão Ambiental, que exige: o estabelecimento de uma política ambiental para os portos; o reconhecimento das interfaces ambientais do porto; o cumprimento da legislação ambiental; a internalização de instrumentos de gestão; a capacitação de pessoal e a estruturação de equipes de gestão e operação para a correta aplicação daqueles instrumentos; e o estudo dos custos ambientais relacionados ao porto".

Portanto as conseqüências e o impacto ambiental das avarias marítimas, são diferentes das avarias portuárias, estas últimas afetam diretamente às áreas urbanas que se encontram ao redor da instalação portuária, muito comum no sistema portuário brasileiro (porto de Santos, Rio de Janeiro, Vitória) e a responsabilidade civil pode recair nos diferentes personagens que participam da logística portuária.

\section{O DEVER FUNDAMENTAL DAS PARTES COMPROMETIDAS NO USO DAS ÁREAS MARÍTIMAS. DESENVOLVIMENTO SUSTENTÁVEL}

Faz-se necessário a implementação de políticas ambientais no âmbito interno dos Estados como uma forma de dever fundamental do conjunto da sociedade a fim de criar um ambiente adequado para a preservação do ecossistema marinho no caso concreto de avarias marítimas e portuárias aperfeiçoando mecanismos de desenvolvimento sustentável a fim de harmonizar os interesses econômicos das empresas envolvidas no transporte internacional de cargas e a preservação do meio ambiente marinho.

Alguns autores entendem que, independente da elaboração de normas, é necessário a criação de espaços territoriais especialmente protegidos,com tecnologia e infraestrutura e mão de obra qualificada para o correto manejo das diferentes espécies e categorias da biodiversidade. Dieguez e Teles ${ }^{10}$ enfatizam que "Como a extinção em massa de espécies é um dos problemas ambientais mais graves vivenciados pelas sociedades humanas na atualidade, a instituição de espaços ambientais vem sendo estimulada ao redor do mundo. Dentre as ares protegidas mais conhecidas, encontram-se os parque nacionais, cuja instituição deu-se a partir do final do século XX, com a criação do parque nacional de Yellowstone, nos EUA, em 1872, experiência rapidamente incorporada por diversos países, ainda no final do século XIX e inicio do século XX".

Uma forma de dever fundamental do Poder Público para a proteção do meio ambiente marinho é a

\footnotetext{
${ }^{9}$ PORTO, Marcos Maia/ GREIN, Teixeira Sérgio. Portos e Meio Ambiente. São Paulo:Aduaneiras, 2001, p. 13.

${ }^{10}$ OLIVEIRA, Carina Costa de (coord.). MEIO AMBIENTE MARINHO E DIREITO: Exploração e Investigação na Zona
} 
implementação destes espaços protegidos, não somente terrestres ( jardins botânicos, hortos florestais, zoológicos etc.) mas também proteção da biodiversidade aquática. Internamente o Brasil, através do Decreto 5.758/06 cria o Plano Nacional de Áreas Protegidas (PNAP), como consequência de compromissos assumidos ao assinar a Convenção sobre Diversidade Biológica, durante a Conferencia das Nações Unidas sobre Meio Ambiente e Desenvolvimento - CNUMAD - em 1992, aprovada por Decreto Legislativo n² de 3 de fevereiro de 1994, e promulgada pelo Decreto no 2.519 , de 16 de março de 1998.

O Decreto estabelece que o Programa de Trabalho para Áreas Protegidas da Convenção sobre diversidade biológica prevê o desenvolvimento de estratégias para estabelecer sistema abrangente de áreas protegidas, ecologicamente representativo e efetivamente manejado, integrado a paisagens terrestres e marinhas mais amplas até 2015 .

O dever fundamental na proteção destas áreas marinhas deve contar também com a participação efetiva dos membros da comunidade, tanto das pessoas físicas como jurídicas posto que a responsabilidade deve ser compartilhada pelo conjunto da sociedade a fim de criar formas de proteção integral para todos os tipos de poluição ambiental marinha, incluindo as causadas por avarias marítimas e portuárias , que finalmente fazem parte do conjunto de resíduos que são jogados no ambiente aquático.

Nesta última parte do trabalho nos questionamos se existe a possibilidade de proteger o meio ambiente e ao mesmo tempo promover políticas de desenvolvimento econômico, fomentando a industrialização através da depredação dos recursos naturais econômico em uma sociedade altamente consumista? A resposta não é simples, posto que existem fatores incontroláveis como o crescimento demográfico em proporção geométrica e a necessidade de produção de alimentos em grande escala, a industrialização global com todas as suas consequências na degradação do meio ambiente rural e urbano.

Na década dos anos 70, surgiram movimentos ambientalistas nos países subdesenvolvidos ou também chamados do Terceiro Mundo que se insurgiram contra as recomendações dos países desenvolvidos, os mesmos que, depois de depredar os seus recursos naturais, tentavam impor exigências de controle ambiental aos países pobres. Clarissa D'Isep" ${ }^{11}$ afirma que ; "Visualizando entre a defesa do meio ambiente e o desenvolvimento econômico, há uma dicotomia, na verdade um antagonismo, criou-se ,na Conferência de Estocolmo/72, nos princípios 5 e 8, a noção de "desenvolvimento sustentável" ( ou "sustentado", ou ainda "ecodesenvolvimento"), que prosperou, ecoando mais tarde em pelo menos onze dos vinte e sete Princípios da Declaração da Rio/92 em especial nos princípios 3 e 4, assim como no setor privado, mediante a sua implementação nos modelos de gerenciamento empresarial - a gestão ambiental”.

Costeira, na Plataforma Continental e nos Fundos Marinhos./Curitiba:Juruá, 2015, p. 253.

${ }^{11}$ D ISEP, Clarissa Ferreira Macedo. Direito Ambiental Econômico e a ISSO 14.000: análise jurídica do modelo de gestão ambiental e certificação ISSO 14001. São Paulo: Editora Revista dos Tribunais, 2004, p. 35. 
O objetivo do principio de desenvolvimento sustentável é a de tentar preservar o meio ambiente através de um uso sadio para as presentes e futuras gerações. Clarissa D 'Isep ensina que :" A característica primordial do eco desenvolvimento é a busca contínua e efetiva de conciliação entre o desenvolvimento, a preservação ecológica e a qualidade de vida do homem"12. Portanto a sustentabilidade foi a saída encontrada para justificar a destruição do meio ambiente pelas empresas e pelo setor privado em geral, a impossibilidade do Poder Público de fiscalizar as múltiplas violações ambientais e a indiferença e negligência da sociedade para evitar o alto grau de degradação ambiental, as mesmas que nos conduzem a um cenário sumamente perigoso e com serias conseqüências para o ser humano.

O dever fundamental de preservar o meio ambiente esta previsto no artigo 225 da CF/88: "Art.225. Todos têm direito ao meio ambiente ecologicamente equilibrado, bem de uso comum do povo e essencial à sadia qualidade de vida, impondo-se ao Poder Público e à coletividade o dever de defendê-lo e preservá-lo para as presentes e futuras gerações" (grifo nosso). Por tanto a conservação e prevenção do meio ambiente é uma responsabilidade compartilhada entre Poder Público e coletividade através do cumprimento dos deveres fundamentais de prevenir e reparar os danos ambientais.

Eduardo Gudynas ${ }^{13}$ citando dois artigos da Constituição equatoriana em relação à sustentabilidade , afirma que: "Es oportuno volver al caso de estúdio ecuatoriano para examinar cómo este concepto fue incorporado por la nueva Constitución, ya que aparece en varias secciones (en cambio em la Constitución de Bolivia las referencias son genéricas). Se indica, por ejemplo, que el Estado debe garantizar un modelo sustentable de desarrollo, ambientalmente equilibrado, que proteja la biodiversidad, y asegure la regeneración natural de los ecosistemas (art. 395), y que el derecho al ambiente sano y ecológicamente equilibrado debe servir a la sostenibilidad (art. 14)." É oportuno voltar ao caso do estudo equatoriano para examinar como este conceito foi incorporado pela nova Constituição, posto que aparece em varias seções ( não entanto na Constituição da Bolívia as referências são genéricas ). Indica-se, por exemplo, que o Estado deve garantir um modelo sustentável de desenvolvimento, ambientalmente equilibrado, que proteja a biodiversidade, e assegure a regeneração natural dos ecossistemas( art. 395), e que o direito ao ambiente sadio e ecologicamente equilibrado deve servir à sustentabilidade (art.14). (tradução nossa).

A única forma de aceitar o conceito de sustentabilidade é através da elaboração de normas constitucionais que reconheçam os valores da natureza, considerando-a como sujeito de direito. "A partir del reconocimiento de que la naturaleza no es infinita, que tiene límites y que estos limites estan a punto de agotarse,

${ }^{12}$ D 'ISEP, Clarissa Ferreira Macedo. Direito Ambiental Econômico e a ISSO 14.000: análise jurídica do modelo de gestão ambiental e certificação ISSO 14001. São Paulo: Editora Revista dos Tribunais, 2004, p. 37.

${ }^{13}$ GUDYNAS, Eduardo. Derechos de la nautaleza y políticas ambientales. La Paz, Bolívia: Plural editores, 2014, p. 172. 
si no lo han sido ya..."14, ou, "A partir do reconhecimento de que a natureza não é infinita, que tem limites e que estes limites estão prestes do esfotamento, se não foram já ..." (tradução nossa). Esta é uma forma justa de compreensão e de toma de consciência da necessidade de entender o dever fundamental compartilhado.

\title{
CONSIDERAÇÕES FINAIS
}

Pelo exposto, podemos concluir que os incidentes marítimos conhecidos na doutrina e na legislação com Avarias Marítimas e Avarias Portuárias, são responsáveis também pela poluição do meio ambiente marinho durante os processos de alijamento de mercadoria ou acidentes marítimos provocados intencionalmente cumprindo seus pressupostos tais como a extraordinariedade, intencionalidade, razoabilidade e em prol da comunidade de interesses, ou seja em beneficio da proteção do navio, mercadoria e segurança da tripulação, ou por negligencia no caso da avaria particular, mas estes atos legais na forma, não são argumentos válidos quando as consequências são totalmente desfavoráveis ao meio ambiente marinho.

Entendemos que é primordial a elaboração de normas especificas para regular e prevenir as formas de poluição marinha como consequência das avarias marítimas e portuárias, assim como a definição da responsabilidade civil para estes fatos.

Finalmente, haja vista o poderoso fator de industrialização numa sociedade altamente consumista e globalizada, fortalecer o princípio do desenvolvimento sustentável ambientalmente equilibrado, assegurando regeneração natural do ecossistema.

\section{THE FUNDAMENTAL DUTY FOR THE PROTECTION OF THE MARINE ENVIRONMENT AS A CONSEQUENCE OF MARITIME AND PORT BREACH}

\begin{abstract}
This articles aims to analyze one of the ways of destructions of the marine environment within the maritime spaces as a result of shipping and transport by sea both in national and international waters. Maritime and Port average as a factor of environmental pollution caused by human deeds. The Maritime and Port average, object of studies of this article, have to be analyzed based upon the article $225 \$ 1^{\circ}$ and $4^{\circ}$ of the Brazilian Constitution and a theoretical basis in the studies of national authors like Eliana Otaviano, Carla Adriana Comitre Gibertoni and Clarissa Ferreira Macedo D' Iesp. Just like the corresponding national legislation as the Commercial Law, International Law as Year 2004 ) York-Antwerp Rules of 2004), asserting that the liability (fundamental torts) has to be shared with Estate, the business entity and the natural person that participate at the maritime endeavor of transportation and carriage of goods by sea.
\end{abstract}

Keywords: Maritime and Port average; Fundamental Torts; Maritime Transport; Sustentability.

\footnotetext{
${ }^{14}$ GUDYNAS, Eduardo. Derechos de la nautaleza y políticas ambientales. La Paz, Bolívia: Plural editores, 2014, p. 8.
} 


\section{REFERENCIAS}

CRENONEZE, Paulo Henrique. Prática de Direito Marítimo: O contrato de transporte marítimo e a responsabilidade civil do transportador. $2^{a}$ ed. Revisada, atualizada e ampliada. São Paulo: Quartier Latin, 2012.

D ' ISEP, Clarissa Ferreira Macedo. Direito Ambiental Econômico e a ISSO 14.000: análise jurídica do modelo de gestão ambiental e certificação ISSO 14001. São Paulo: Editora Revista dos Tribunais, 2004.

GIBERTONI, Carla Adriana Comitre. Teoria e Prática do Direito Marítimo. 3.ed, atualizada, revista e ampliada. Rio de Janeiro: Renovar, 2014.

GUDYNAS, Eduardo. Derechos de la nautaleza y políticas ambientales. La Paz, Bolívia: Plural editores, 2014.

OCTAVIANO MARTINS, Eliane Maria. Curso de direito marítimo., volume II. Barueri, SP: Manole,2008.

OLIVEIRA, Carina Costa de (coord.). Meio ambiente marinho e direito: Exploração e Investigação na Zona Costeira, na Plataforma Continental e nos Fundos Marinhos./Curitiba:Juruá, 2015.

PORTO, Marcos Maia/ GREIN, Teixeira Sérgio. Portos e Meio Ambiente. São Paulo:Aduaneiras, 2001

SILVA, Francisco Carlos Morais. Manual de Direito Portuário. Vila Velha: Above publicações, 2013.

Trabalho enviado em 22 de junho de 2017.

Aceito em 03 de novembro de 2017. 